\title{
Sporadic Breast Carcinoma
}

National Cancer Institute

\section{Source}

National Cancer Institute. Sporadic Breast Carcinoma. NCI Thesaurus. Code C7566.

A carcinoma that arises from the breast and is not caused by inherited genetic

mutations. 